\title{
Use of an Implant O-Ring Attachment for the Tooth Supported Mandibular Overdenture: A Clinical Report
}

\author{
Satyabodh S. Guttala \\ Anand K. Tavargerib \\ Ramesh K. Nadigera \\ Srinath L. Thakur ${ }^{\mathrm{C}}$
}

\begin{abstract}
Retention of a mandibular denture can be achieved by an implant-retained or natural toothretained bar and stud attachment in the anterior segment of the mandible. The same design principles holds true for both implant-retained and tooth-retained methods of anchoring the bar and stud attachment. A simple and cost effective treatment for more complex implant overdenture is the concept of conventional tooth-retained overdentures. When few firm teeth still remain in a compromised dentition, preservation of these teeth for overdentures can improve retention and stability. The authors present a clinical report of a patient treated with a mandibular tooth-borne overdenture with bar and 0-ring attachment. A splinted bar supported the prosthesis and an 0-ring retained the denture. (Eur J Dent 2011;5:331-336)
\end{abstract}

Key words: Overdenture; Implant; Retention.

\section{INTRODUCTION}

Retaining teeth for an overdenture is an old concept and a viable treatment modality. ${ }^{1-4}$ Overdentures provide better function than conventional complete dentures through a variety of factors, such as improved biting force chewing efficiency, and increased speed of controlled mandibular

a Department of Prosthodontics, SDM College of Dental Sciences and Hospital, Dharwad, Karnataka, India.

b Department of Pedodontics, SDM College of Dental Sciences and Hospital, Dharwad, Karnataka, India. Department of Oral Implantology, SDM College of Dental Sciences and Hospital, Dharwad, Karnataka, India.

- Corresponding author: Dr. Satyabodh S. Guttal Department of Prosthodontics, SDM College of Dental Sciences and Hospital,

Sattur, Dharwad - 580 009, Karnataka, India.

Fax: 91-836-2467612

E-mail: drsatyabodhayahoo.co.in movement. ${ }^{5}$ In addition, they minimize the downward and forward setting of a denture, which otherwise occurs with alveolar bone resorption. ${ }^{6}$ The key to success of an overdenture is the selection of strategic roots or teeth for retention. Elective endodontics and periodontal therapy make them excellent abutments for an overdenture. Abutment teeth are prepared, to create adequate space for the overlying denture. The shortened crown improves the crown-to-root ratio, thereby decreasing the motility of the abutment teeth under an overdenture. ${ }^{7}$ In a 4-year-study, Renner et al ${ }^{8}$ showed that $50 \%$ of roots, used as overdenture abutments remained immobile. In addition, $25 \%$ of roots that were initially mobile became less mobile. Hence, they suggested, that teeth that are generally compromised can be used for overden- 
tures after root canal therapy and decoronation.

The use of attachments can redirect occlusal forces away from weak supporting abutments and onto soft tissue, or redirect occlusal forces toward stronger abutments and away from soft tissues. They act as shock absorbers and stress redirectors as well as providing superior retention. Attachments are often used in overdenture construction by either connecting the attachments to cast abutment copings or connecting into the prepared post space of the abutment teeth. Overdenture attachments are classified either as studs, which connect the prosthesis to the individual tooth, or as bars which connect the prosthesis to the splinted abutment teeth. They are further classified as rigid or resilient. However, since edentulous ridges and the remaining roots are often compromised, the prosthesis that relies on resilient attachments is better able to divert occlusal forces away from weak abutment teeth. The metal 0-ring attachment system is considered to be a good resilient attachment for overdentures. 9,10

Bar attachments are commonly used for overdentures. They provide a splinting mechanism between the overdenture abutment teeth and increase the stability and retention of the prosthesis. ${ }^{11,12} \mathrm{~A}$ common bar attachment assembly for overdenture is the one-piece cast bar, connecting to the copings that are luted to abutment teeth. The design of combined bar and 0-ring retained denture is most common for an implant supported overdenture. There are no reports in the literature with regard to the use of this design in toothborne overdentures. This clinical report describes the use of bar and 0-ring stud attachments to retain tooth-borne mandibular dentures. The 0 -ring stud attachment used in the report was replicated from an implant prosthetic component.

\section{CASE REPORT}

A 40-year-old male patient reported to Shree Dental Practice Dharwad, Karnatak, India. The patient complained of several loose teeth in the lower arch. On examination, all of the lower incisors and teeth numbered 47, 46, 44, 34, 35 and 36 were mobile. The patient was advised to have those teeth extracted. Two weeks after extraction, the patient reported for replacement of the missing teeth. The teeth present in the lower arch were 45, 43, 33 and 37 (Figure 1). All of these were firm apart from 33 which had grade I mobility. Radiographic examination revealed adequate bone support. The option of an Overdenture and the approximate cost were discussed with the patient. The patient was interested in the suggested treatment plan.

Diagnostic casts were articulated at the anticipated vertical dimension of occlusion. Vertical dimension recording was easier because of the presence of a premolar on the right side. The diagnostic articulation helped in assessing the available inter-arch space and this was found to be adequate. Proposed abutment teeth numbered 33, 43 and 45 were prepared on the diagnostic cast, and the ability to accommodate abutment copings, bar and 0-ring attachments was assessed. After careful planning, a final treatment plan was given to the patient with fabrication of a mandibular overdenture with bar and 0-ring attachment. Elective endodontics was carried out with teeth 45, 43 and 33 . Abutment teeth were prepared in a dome-shaped contour and hemispherically rounded in all dimensions. The height of the abutment teeth was 3-4 $\mathrm{mm}$ projecting just above the gingiva. The exposed dentin of the abutment was polished and treated with fluoride varnish. A rubber base impression (Figure 2) was made and a cast poured in die stone.

The 0-ring attachment used for the implant overdentures consisted of a brass abutment analogue, metal 0 -ring, and white and red color silicone rings. The laboratory analogue was duplicated in putty rubber base relined with light body polyvinylsiloxane. Pattern resin was poured into the duplicate mold to fabricate the castable stud attachment (Figure 3). The metal 0-ring with silicone ring fitted well with the duplicate pattern resin abutment analogue (Figure 4). The excess dowel length of the pattern resin was removed. A wax pattern was made for the bar framework. The abutment teeth were connected using $2 \mathrm{~mm}$ sprue former wax. The duplicate pattern resin stud attachment was waxed to the bar framework (Figure 5). Two stud attachments were placed. One of the studs was attached to the distal aspect of tooth 45 and another to the mesial aspect of tooth 33 above the bar. The casting of the framework was done in Co-Cr alloy using conventional procedures. The bar framework with stud attachments was finished and polished. It was tried in the patient's mouth and the fit was satisfactory. The bar and 
stud framework was luted to the abutment teeth using resin cement (Figure 6).

After the cementation of the bar framework, a final impression of the lower arch was made using medium body rubber base material. Care was taken to block the undercuts below the bar with soft wax at the time of impression making. Brass abutment analogues which were previously used for duplication were placed in the impression and a master cast was poured in dental stone (Figure

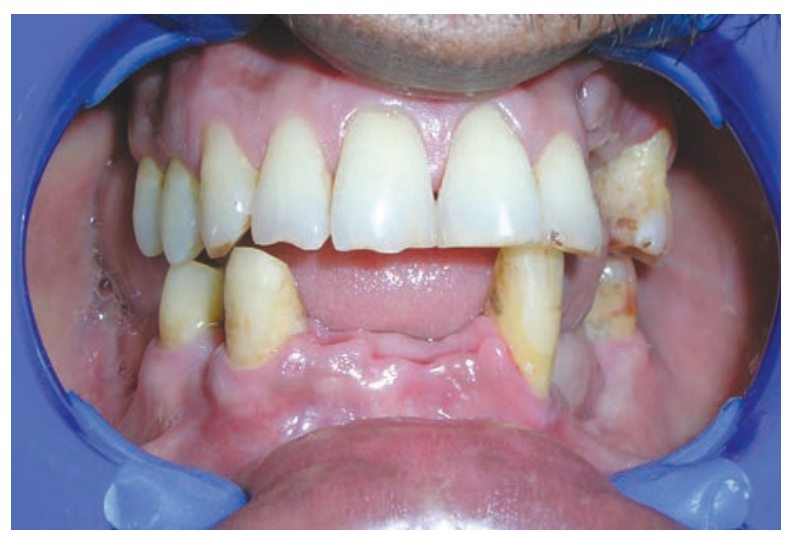

Figure 1. Image of patient's remaining firm teeth.

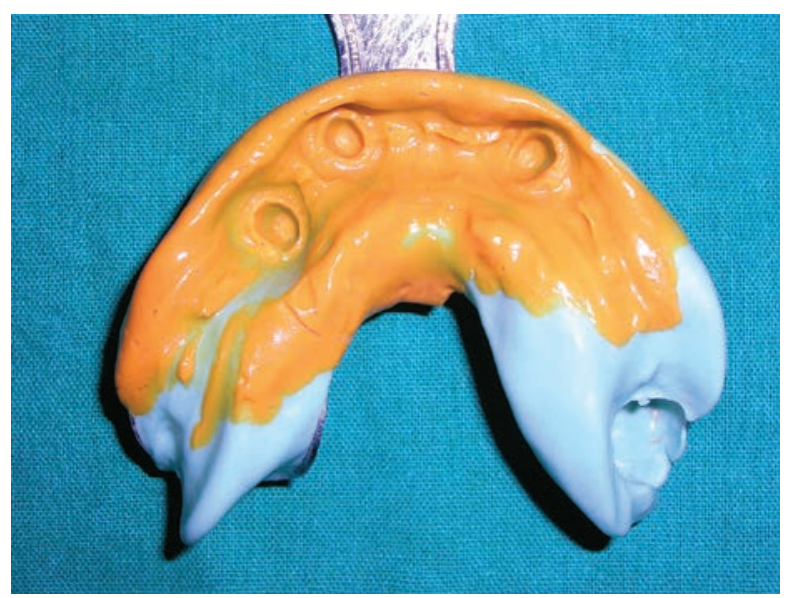

Figure 2. Rubber base impression after tooth preparation for bar framework fabrication.

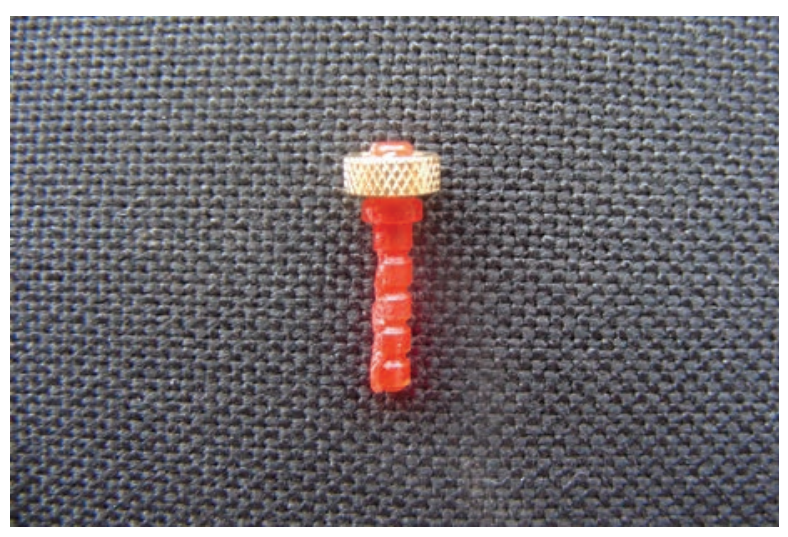

Figure 4. Metal 0-ring fitting well to the resin post.
7). The metal 0-ring was placed on the laboratory analogues on the master cast and a record base was fabricated. A relief block-out was performed around the attachment for easy removal of the record base. A record rim was made and the jaw relationship recorded using conventional techniques. Teeth arrangement was done and a trial was made. After a satisfactory trial, the trial denture was invested and dewaxed. The metal 0-rings were retrieved from the temporary record base and were placed on the abutment analogue (Figure 8). Block out was performed beneath the 0 ring. Heat polymerizing acrylic resin was packed and cured. Finishing and polishing of the processed denture were carried out. Relief was provided around the 0 ring and bar framework area so that no movement of the framework occurred as the denture base was moved slightly on and off the tissues (Figure 9). Fit checker disclosing agent was used for this purpose to identify contact between the attachment mechanisms and the denture base. Finally the denture was placed (Figure

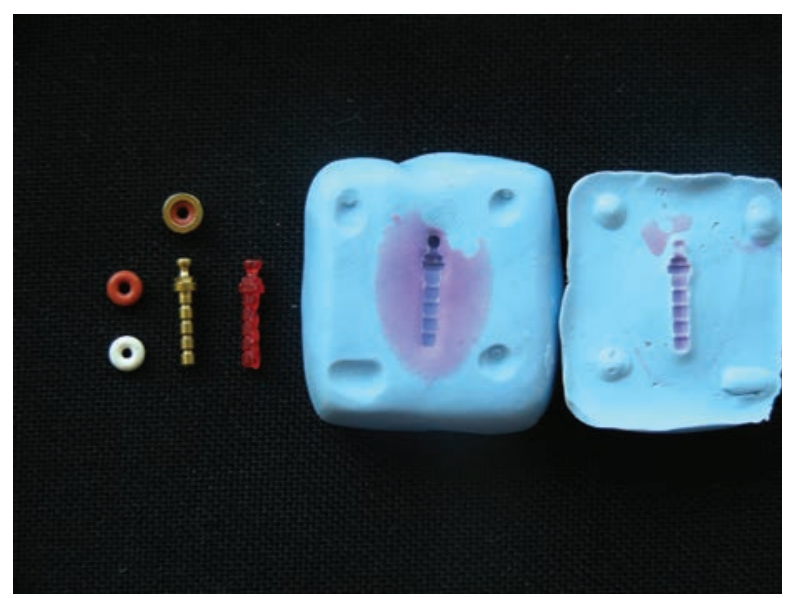

Figure 3. 0-ring attachment system with duplicated pattern resin post in putty index.

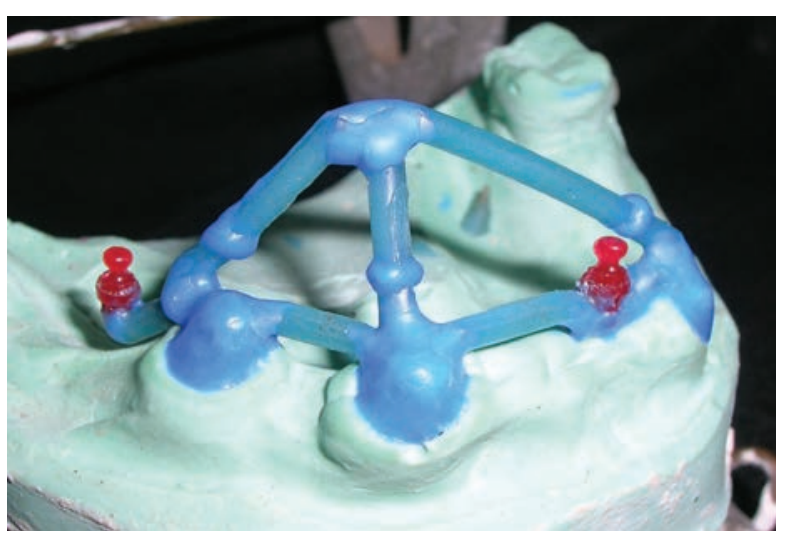

Figure 5. Wax pattern of the bar framework with the duplicated resin studs attached.

July 2011 - Vol.5 
10). It had a passive fit with the simultaneous accurate fit of the denture base on the mucosa and the 0-ring attachments without any rocking movement. A post-operative radiograph was taken after 1-year to evaluate the abutments. They were found to be satisfactory (Figure 11).

\section{DISCUSSION}

The use of teeth as overdenture abutments is beneficial to patients. The psychological aspect of patients losing teeth should not be underestimated and this has been well documented. ${ }^{13}$ Careful selection of strategic abutment is important. The

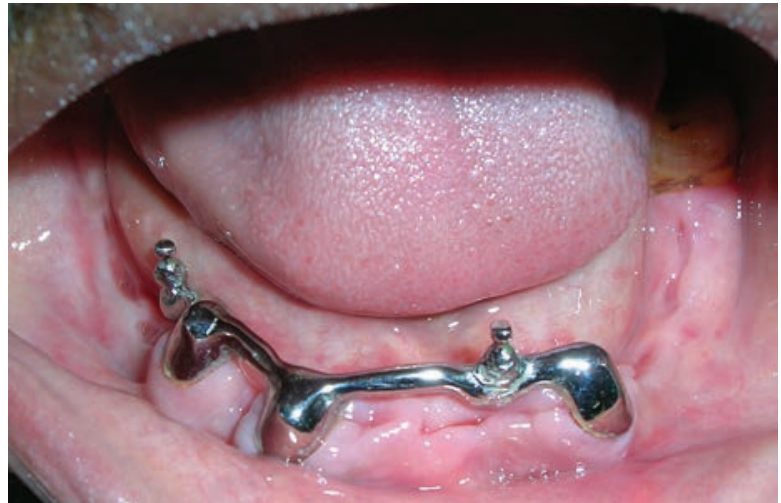

Figure 6. Cemented bar framework.

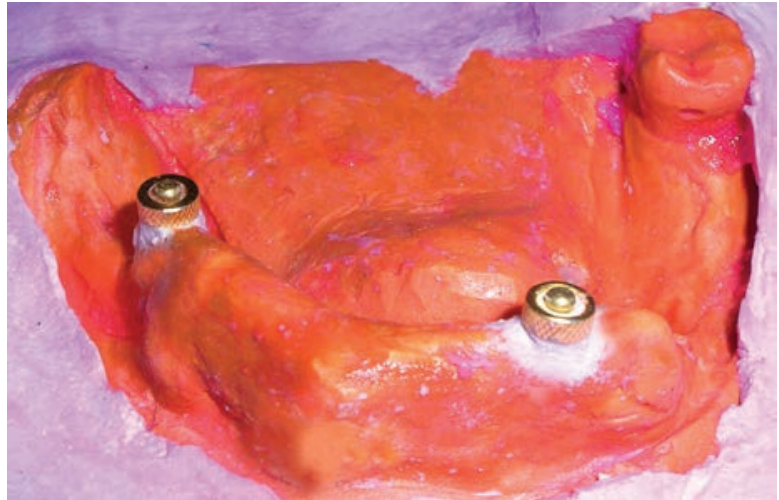

Figure 8. Wax elimination complete and the 0-rings placed on the laboratory analogues.

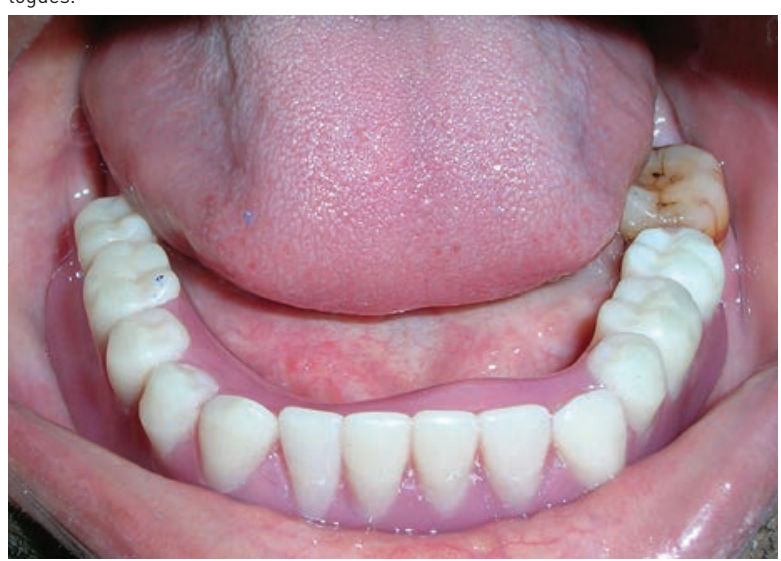

Figure 10. Prosthesis in-situ. decision must first be made to retain the teeth as overdenture abutments and then the attachments should be planned. The attitude of the patient to the treatment should be assessed. Only those who understand the limitations and benefits of attachments should be treated with attachment retained overdentures. Hence, patient selection is critical to the success of the treatment.

Tooth-borne overdenture bar attachment therapy is a treatment option rarely chosen in today's aggressive marketing of implant treatment. ${ }^{14}$ Most of the reported cases in the literature on the combination of bar and 0-ring attachment overdentures are implant supported. ${ }^{15,16}$ In the reported

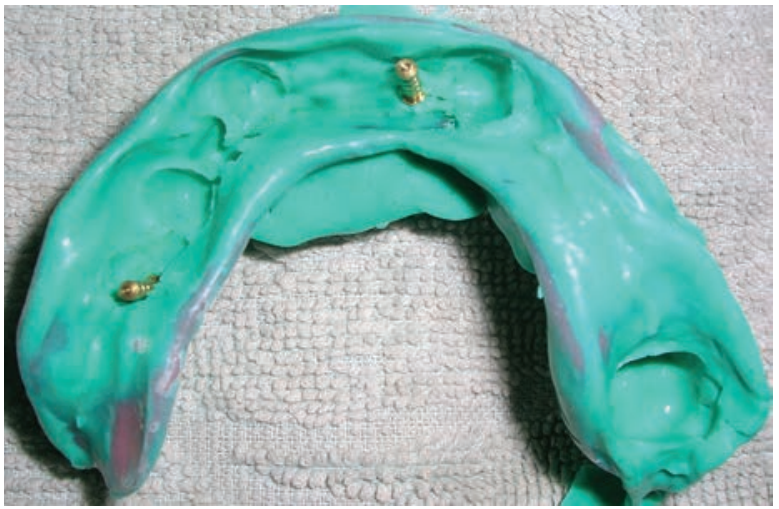

Figure 7. Final impression for the denture fabrication.

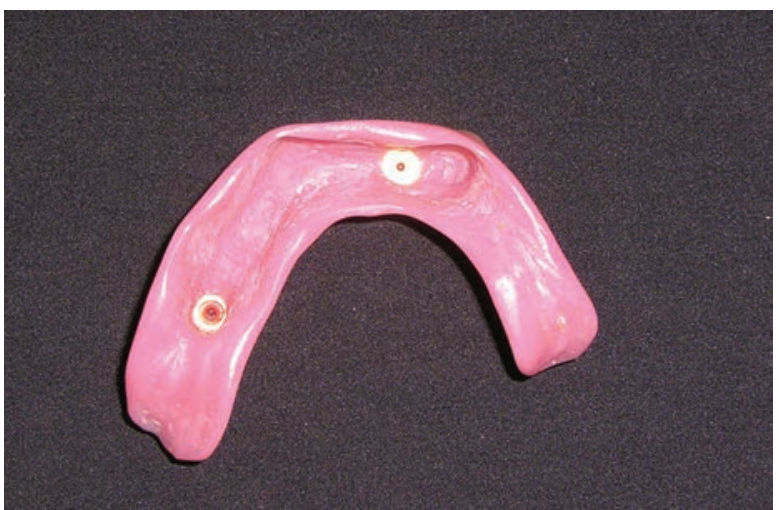

Figure 9. Tissue surface of the denture showing the embedded female attachments.

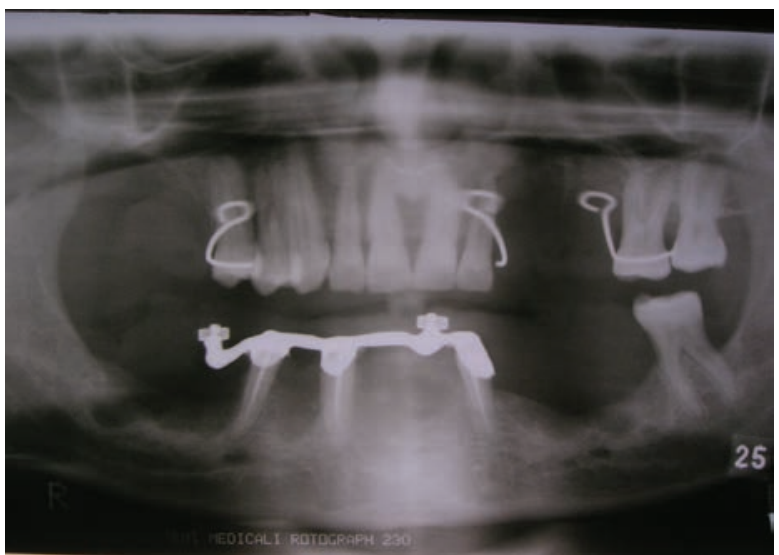

Figure 11. Post operative $O P G$

European Journal of Dentistry 
literature, ${ }^{17-21}$ tooth supported overdentures are retained by stud attachments and there are very few reports with regard to bar/clip attachment. ${ }^{22,23}$ The use of bar and 0 -ring attachment is very rare for the tooth supported overdenture.

In the present report, a bar and 0 -ring retained mandibular denture was fabricated. The 0-ring attachment used was basically the implant prosthetic component. The 0 -ring is functionally classified as a resilient attachment. It does not transfer forces to the root and only acts as a retentive devices. Hence, the 0 -ring system is considered to be the best attachment that acts passively on the remaining abutment teeth. ${ }^{24}$ It also provides adequate retention, is easy to insert/remove and is comfortable for the patient. There are however, some disadvantages such as the gradual loss of retention due to the wear of 0 -rings, and the need for periodic replacement. Rodrigues et $\mathrm{al}^{25}$ conducted a study to evaluate the retention force of an 0 -ring attachment system at different inclinations to the ideal path of insertion. They concluded that 0 -ring studs perpendicular to the occlusal plane were adequately retentive over the first year and that the retentive capacity of the 0 -ring was affected by stud inclinations. The 0-ring studs were perpendicular to the occlusal plane. A surveyor was used for this reason, and the studs were placed parallel to each other without any inclinations.

A bar attachment was used since this provided the splinting mechanism between the overdenture abutment teeth which stabilized and strengthened the abutment teeth. The bar also allowed the forces of mastication to be shared by the abutment teeth. ${ }^{12,26}$ Various bar attachment methods are used for overdenture bar fabrication. ${ }^{12,27-28}$ But since the bar was used to connect the abutment teeth and not to retain the clip on it, a $2 \mathrm{~mm}$ round sprue former was used for bar fabrication. The bar and stud framework was luted to the teeth using adhesive cement. An intra-canal dowel extension was not used for the copings since the teeth were not parallel.

One of the 0-ring studs was placed on the distal aspect of the right lateral abutment and another was placed mesial to the left lateral abutment. Since the bone support on the distal aspect of the left lateral abutment was compromised, the stud was placed mesially so as to prevent the forces of insertion/removal endangering the abutment. In the present clinical situation, there was $21 \mathrm{~mm}$ of inter-occlusal clearance. Hence the stud attachment was incorporated above the bar on the mesial aspect of the left lateral abutment.

The bar was contoured and the intaglio surface of the prosthesis was relieved. This allowed freedom of movement for the 0 -ring attachment when the denture base moved slightly.

The bar and 0 -ring retained overdenture showed good retention. The patient was pleased with the treatment and was satisfied with the esthetics and function of the denture. Homecare hygiene instructions and dietary advice with regard to caries control were reinforced. The patient was advised to clean the bar and attachment with a interdental tooth brush using warm salt water. Initially, follow-up was once a week for a month. Later evaluation was done once in every 6 months. At the time of follow-up, routine maintenance such as oral prophylaxis was carried out. The denture has been in use for 2 years now without any problems and the patient is extremely pleased with it.

\section{CONCLUSIONS}

Lack of retention of complete mandibular dentures is a common complaint among the complete denture patients. With the inception of osseointegrated implants, the concept of overdentures has become more popular, but not all patients are able to afford the treatment costs. A tooth-borne overdenture may be advised whenever several good teeth remain in the arch. The different bar and stud attachment designs suggested in the literature for implant overdentures also hold true for tooth-borne overdentures. The incorporation of attachments in overdentures into everyday dental practice will open up another dimension in dental treatment planning and patient satisfaction. Teeth that might be considered for extraction may be considered as long or short term alternatives to implant or total edentulousness.

\section{REFERENCES}

1. Tallgren A. Changes in adult face height due to aging, wear, loss of teeth and prosthetic treatment. Acta Odontol Scand $1957 ; 15: 24$.

2. Brill N. Adaptation and the hybrid prosthesis. J Prosthet Dent 1955;5:811-823. 
3. Miller PA. Complete dentures supported by natural teeth. $J$ Prosthet Dent 1958;8:924-928.

4. Prince JB. Conservation of the supportive mechanism. $J$ Prosthet Dent 1965;19:327-338.

5. Rissin L, House JE, Manly RS, Kapur KK. Clinical comparison of the masticatory performance and electromyographic activity of patients with complete dentures, overdentures, and natural teeth. J Prosthet Dent 1978;39:508.

6. Crum RJ, Rooney GE. Alveolar bone loss in overdentures; a 5-year study. J Prosthet Dent 1978;40:610-613.

7. Lovdal A, Schei O, Waerhaug J. Tooth mobility and alveolar bone resorption as a function of occlusal stress and oral hygiene. Acta Odontol Scand 1959;17:61-75.

8. Renner RP, Gomes BC, Shakeen ML. Four year longitudinal study of the periodontal health status of overdenture patients. J Prosthet Dent 1984;51:593-598.

9. Tokuhisa M, Matsushita Y, Koyan K. In vitro study of a mandibular implant overdenture retained with ball, magnet, or bar attachment: comparison of load transfer and denture stability. Int J Prosthodont 2003;16:128-134.

10. Ben-Ur Z, Gorfil C, Shifman A. Anterior implant supported overdentures. Quintessence Int 1996;27:603-606.

11. De Franco RL. Overdentures In: Winkler S, ed. Essentials of complete denture Prosthodontics. 2ed Littleton, MA: PSG Publishing Co, 1988; pp 384-402.

12. Preiskel HW. Precision attachments in prosthodontics; overdentures and telescopic prostheses. Vol 2 Chicago, IL; Quintessence Publishing Co, 1985; pp 243-306, 350-351.

13. Fiske J, Davis DM, Frances C, Gelbier S. The emotional effects of tooth loss in edentulous people. BDJ 1998;184:9093.

14. Williamson RT. Retentive bar overdenture fabrication with preformed castable components. A case report. Quintessence Int 1994;25:389-394.

15. English CE. Bar patterns in implant prosthodontics. Implant Dent 1994;3:217-229.

16. Ben-Ur Z, Gorfil C, Shifman A. Anterior implant supported overdentures. Quintessence Int 1996;27:603-606.

17. Assemat T, Amzalag G. Overlay dentures with push button type axial attachment use of isolated roots for retention of overlay dentures. Inf Dent 1990;72:867-875.

18. Pavlatos J. The root supported overdenture using the locator overdenture attachment. Gen Dent 2002;50:448-453.

19. Pavlatos J. Root supported overdentures. CDS Rev 1998;91:20-25.

20. Langer $Y$, Langer A. Root retained overdentures Part I Biomechanical and clinical considerations. J Prosthet Dent 1991;66:784-789.

21. Bureau GP. Tooth supported stud retained prosthesis. Dent Update 2003;30:389-394.
22. Evans BD, Koeppen GR. Bar attachment for overdentures with non parallel abutments. J Prosthet Dent 1992;68:6-11.

23. Marquardt GL. Dolder bar joint mandibular overdenture. Atechnique for non parallel abutment teeth. J Prosthet Dent 1976;36:101-111.

24. Bambara EG. The attachment retained overdenture. NYSDJ 2004;70:30-33.

25. Rodrigues RC, Faria AC, Macedo AP, Sartori IA, de Matros MD, Ribeiro RF. An in vitro study of non-axial forces upon the retention of an O-ring attachment. Clin Oral Implants Res 2009;20:1314-1319.

26. Renner RP. Complete dentures: A guide for patient treatment. New York: Masson Publishing USA, 1981 pp 257-271.

27. Dolder EJ. The bar joint mandibular denture. J Prosthet Dent 1961;11:689-707.

28. Guttal SS, Nadiger RK. Use of coffee straw for overdenture bar fabrication. J Prosthet Dent 2009;102:266. 